\title{
Effect of Adenoid Hypertrophy on Otitis Media with Effusion (OME): A Study of 120 Pediatric Cases
}

\author{
Islam MA ${ }^{1 *}$, Mamoon TB ${ }^{2}$, Milki FU ${ }^{3}$, Mohammad T ${ }^{4}$, Lutfur ASM ${ }^{5}$, Chowdhury NH$^{6}$, Khan SR $^{7}$ and Arefin \\ $\mathrm{MK}^{8}$ \\ ${ }^{1}$ Professor and Head, Otolaryngology-Head \& Neck Surgery, Bangladesh Medical College Hospital, Bangladesh
}

${ }^{2}$ Assistant Registrar, ENT, Bangladesh Medical College Hospital, Bangladesh

${ }^{3}$ Consultant ENT, Bangladesh Medical College Hospital, Bangladesh

${ }^{4}$ Assistant Registrar ENT, Bangladesh Medical College Hospital, Bangladesh

${ }^{5}$ Resident Surgeon, Bangladesh Medical College Hospital, Bangladesh

${ }^{6}$ Assistant Professor, ENT, Bangladesh Medical College Hospital, Bangladesh

${ }^{7}$ Assistant registrar, ENT, National Institute of ENT, Bangladesh

${ }^{8}$ Otolaryngologist, Dhaka Medical College Hospital, Bangladesh

*Corresponding author: Ashraful Islam, Professor and Head Department of Otolaryngology-Head \& NeckSurgery, Bangladesh Medical College, Dhaka, Bangladesh.
Received Date: August 14, 2020

Published Date: August 25, 2020

\section{Abstract}

Background \& Objectives: Otitis media with effusion (OME) is a common cause of diminished hearing in children younger than 15 years. Hypertrophy of adenoids is one of the commonest etiologies of this condition. This study compares the efficacy of adenoidectomy on OME in patients with different grades of adenoids and the connection between different position of adenoids and middle ear effusion.

Methods: This is a prospective study done on 120 pediatric patients ( 2 to 15 year) presented with chronic otitis media with effusion and adenoid hypertrophy from 2017 to 2019. Adenoid size was graded and correlated with the type of tympanometry. All the cases were subjected to adenoidectomy and myringotomy with or without ventilation tube insertion. They were observed every 3 months postoperatively for a period of 3 years. Preoperative and postoperative data were collected and comparison was made to evaluate whether adenoidectomy with myringotomy is sufficient on management of OME.

Results: Adenoid tissue grading showed majority of population remained in Grade III (45\%) and Grade C (56.67\%). There is a highly significant relation between higher adenoid grade and type B tympanometry. This study showed significant association between grade III and grade C adenoid hypertrophy and otitis media with effusion when compared with other grades of adenoid hypertrophy. This suggests that increasing grade of adenoid hypertrophy is important predictor in establishment of otitis media with effusion in patient with adenoid hypertrophy. After adenoidectomy majority of tympanometry curve was shifted from type B to type A. In case of Grade III, type B tympanometry reduced from 45 to 11 ( $83 \%$ to $20 \%$ ) in right ears; 49 to 7 (90\% to $12 \%)$ in left ears. Again, in case of Grade C, type B tympanometry reduced from 55 to $6(80 \%$ to $8 \%)$ in right ears; 58 to $5(85 \%$ to $7 \%)$ in left ears. This change was significant. The greater the size of the adenoid, after adenoidectomy, more improvement noticed in tympanometry curve.

Conclusion: This study may not be the actual picture of overall situation due to many limitations. Still it can be concluded that enlarged adenoids has a definite role in causing OME. This research also shows a benefit of adenoidectomy in the removal of middle ear effusion in children with OME. To efficiently assess the efficacy of adenoidectomy for otitis media with effusion in children, future research is needed.

Keywords: OME; Adenoid hypertrophy; Adenoid grading; Tympanometry; Adenoidectomy 


\section{Introduction}

The adenoids are lymphoid tissue, located behind the nose and soft palate; normally present in all children. They are susceptible to frequent infections of their nose and throat, resulting enlarged adenoids which cause obstructing nasal breathing. Since the adenoids are close to the Eustachian tube, their enlargement or infection may contribute to recurring diseases such as acute or chronic otitis media, Eustachian tube dysfunction, otitis media with effusion (OME) etc. OME is a very common disease; approximately $90 \%$ of children $(80 \%$ of individual ears) have it at some point before reaching school age, often from 6 months to 4 years of age. Spontaneous resolution occurs usually within 3 months, but $30 \%$ to $40 \%$ of children develop recurrent OME, and $5 \%$ to $10 \%$ of the episodes last 1 year or longer [1,2].

OME is defined as the presence of fluid in the middle ear in the absence acute middle ear infections potentially leading to hearing loss or long-term sequel and has a negative impact on speech development and behaviour [3]. Serous or mucoid fluid tends to accumulate in the middle ear due to negative pressure. The size of the adenoids varies from patient to patient and also in the same individual as he/she grows. In general the normal adenoids attain their maximum size between the ages of 3 and 7 years and then usually regress [4].The important points are taken into consideration for the harmful effects of the adenoids. These are not only depend on the absolute size but more on the size in relation to the space of the nasopharynx [5]. Adenoid hypertrophy (AH) and Eustachian tube dysfunction are known etiological factors for OME.6 Adenoid acts as a reservoir for bacteria as well as a mechanical barrier that blocks the Eustachian tube lumen leading to formation of negative pressure in the middle ear resulting transudation that become middle ear effusion [7]. Different studies showed that the risk of OME increases with increasing nasopharyngeal obstruction and adenoid size seen either by X-ray nasopharynx or nasoendoscopy findings or both $[8,9]$.

This X-ray is very useful in assessing whether the adenoids are obstructing the Eustachian area. A rough estimate of the adenoidal size can also generally be obtained by noting the size of the tonsils. If the tonsils are very large, the adenoids are usually enlarged. The adenoids themselves, however, may be enlarged without significant tonsil enlargement. Different grading systems for adenoid hypertrophy have been introduced in the literature depending on its relation to the choanae [10], Vomer [11] or torus tubarius, vomer, and soft palate.12 Adenoidectomy can remove the adenoids, thereby, restoring mucus drainage and normal pressure in the middle ear affecting the ability of pathogens to invade and reside within the middle ear space. However, at present the effectiveness of adenoidectomy in children with OME remains uncertain and practice is experience-based rather than evidence based. Practice differed surgeon from surgeon. The present study evaluates the relationship between the position and size of adenoid with Eustachian tube dysfunction and middle ear effusion, as well as to obtain a more comprehensive estimate of the adenoidectomy on OME. This has been evaluated:

1. Clinically symptomatic assessment and proper otological examination

2. Diagnostic nasal endoscopy- To assess the status of Eustachian tube orifice and adenoid size

3. Impedence audiometry- documentation of tympanometric curve (B or C) corresponding with OME.

\section{Objectives}

1. To correlate between increased chances of OME with adenoid size and position.

2. To assess the efficacy of adenoidectomy for otitis media with effusion in children.

\section{Materials and Methods}

Study design: prospective study.

Study population: Children with symptoms of OME presenting to the outdoor department of ENT in Bangladesh Medical and Popular Medical College Hospital.

Study sample: 120 patients

Sampling technique: Simple random sampling.

Study period: 2 years (2017-2019).

\section{Study places:}

1. Bangladesh Medical College Hospital.

2. Popular Medical College Hospital.

\section{Inclusion criteria}

1. Age 2 to 15 years.

2. Documented history of OME of at least 3 months.

3. Proof of middle ear effusion documented by tympanometry type B or C.

4. Adenoid hypertrophy documented by the X-ray soft tissue nasopharynx lateral view and endoscopic examination.

Patients whose guardians gave the consent for surgery and study.

\section{Exclusion criteria}

1. Refusing consent for the study.

2. Any contraindication for surgery as acute infection, cleft palate or blood dyscrasias.

\section{Procedure}

1. At first whole study procedure was described to all patients' guardians \& then informed written consent had been taken. 
2. Standardized history and findings of each child was recorded including otoscopic examination of ear, endoscopic examination of nasopharynx and tympanometry result.

3. Diagnosis of OME was based on presence of fluid in the middle ear or dull retracted unilateral or bilateral ear drum/s.

4. Impedance tympanometry was done in all patients and unilateral or bilateral type B and C tympanometry was documented as OME.

5. In order to avoid disease duration bias, a fixed duration of - no response to medical treatment- 3 months had been used in all cases irrespective of the adenoid size.

6. A classification of adenoid size by X-Ray soft tissue nasopharynx lateral view has been described by Clemens et al.

a) Grade I- Adenoid tissue filling one-third of the vertical portion of the choanae.

b) Grade II- Adenoid tissue filling from one-third to twothirds of the choanae.

c) Grade III- From two-thirds to nearly complete obstruction of the choanae.

d) Grade IV- Complete choanal obstruction.

7. Another grading of adenoid tissue was done by flexible endoscopy, depending on the adenoid relation to torus tubarius, vomer, and soft palate when at rest [12]

According to this protocol, 4 grades of adenoid hypertrophy had been documented.

a) Grade A- No relation between the small adenoid and any of the structures mentioned.

b) Grade B- Relation with torus tubarius only.

c) Grade C- Relation with torus tubarius and vomer.

d) Grade D- Relation with torus tubarius, vomer, and soft palate.

8. All the cases were subjected to adenoidectomy and myringotomy with or without ventilation tube insertion. They were observed every 3 months, at which time an examination of the ear, nasopharynx and tympanometry were performed for 3 years or until tympanometry type A curve occurred.

9. Correlation between the type of tympanometry result and adenoid size had been studied as well as relation between the type of fluid in the middle ear observed during the surgical procedure and adenoid size.

10. Preoperative and postoperative data were collected and comparison was made to evaluate whether adenoidectomy with myringotomy had significant role on management of OME.

\section{Results}

This is a prospective study that has been done in Bangladesh Medical College Hospital and Popular Medical College Hospital in the period from 2017 to 2019. It included 120 pediatric patients aged 2 to 15 years. All the cases had documented history of OME of at least 3 months with no response to medical treatment. In the present study the male to female child ratio was $1.4: 1$. The most commonly affected subjects belonged to 6-9 years of age of life in both sexes. (Table 1) shows the sex and age distribution.

Grading of adenoid tissue was done. Two methods of grading were adopted; according to size of adenoid tissue and another one according to relation of adenoid with torus tubarius, vomer and soft palate. (Table 2,3) represents grading and frequency of adenoids. In both grading methods majority of population remained in Grade III (45\%) and Grade C (56.67\%).

Among all OME patients with adenoid hypertrophy common symptoms were hearing impairment, mouth breathing, snoring and nasal discharge. These symptoms were mild in case of Grade I and Grade A categories. In case of Grade III and IV patients, $100 \%$ presented with hearing impairment. Mouth breathing and snoring were prevalent in $96 \%$ or more patients in Grade III and IV categories. In case of Grade C and Grade D, hearing impairment was present in $97 \%$ and $100 \%$ patients respectively. Mouth breathing and snoring were present in $97 \%$ or more patients in Grade C and Grade D. (Table 4,5) shows distribution of symptoms according to different adenoid grading.

In this study, the most frequent tympanometry type was type B. In case of Grade I adenoid, majority of tympanometry was type A; 10 in right ears and 11 in left ears. With more the size of the adenoid, the more frequent type B tympanometry. Here (Table 6) shows, in case of Grade III and Grade IV adenoid most of the tympanometry was type B; 45 and 5 respectively in right ears; 49 and 4 in left ears. Similar results showed in Grade C and Grade D. Majority of patients showed type B tympanometry; 55 and 22 respectively in right ears; 58 and 23 in left ears. (Table 6,7) shows correlation between different grading of adenoid tissue and tympanometry type.

Table 1: Sample distribution of subjects according to age and gender $(n=120)$.

\begin{tabular}{|c|c|c|c|c|}
\hline Gender & $\mathbf{2 - 6}$ years & $\mathbf{7 - 1 0}$ years & $\mathbf{1 1 - 1 5}$ years & Total \\
\hline Male & 28 & 34 & 12 & 70 \\
\hline Female & 17 & 21 & 20 & 50 \\
\hline Total & 45 & 55 & 120 \\
\hline
\end{tabular}


Table 2: Grading of adenoid tissue according to size $(n=120)$

\begin{tabular}{|c|c|c|}
\hline Grading & Frequency & Percentage \% \\
\hline Grade I & 16 & 13.33 \\
\hline Grade II & 44 & 36.67 \\
\hline Grade III & 54 & 45 \\
\hline Grade IV & 6 & 5 \\
\hline Total & 120 & 100 \\
\hline
\end{tabular}

Table 3: Grading according to position of adenoid tissue $(n=120)$.

\begin{tabular}{|c|c|c|}
\hline Grading & Frequency & Percentage \% \\
\hline Grade A & 8 & 6.67 \\
\hline Grade B & 20 & 16.67 \\
\hline Grade C & 68 & 56.67 \\
\hline Grade D & 24 & 20 \\
\hline Total & 120 & 100 \\
\hline
\end{tabular}

Table 4: Distribution of symptoms according to size of adenoid tissue $(n=120)$.

\begin{tabular}{|c|c|c|c|c|}
\hline Features & Grade I & Grade II & Grade III & Grade IV \\
\hline Hearing impairment & 16-Aug & $28 / 44$ & $54 / 54$ & 6-Jun \\
\hline Mouth breathing & $16-\mathrm{Apr}$ & $35 / 44$ & $52 / 54$ & 6-Jun \\
\hline Snoring & $16-\mathrm{Mar}$ & $30 / 44$ & $53 / 54$ & 6-May \\
\hline Nasal discharge & 16-Feb & $15 / 44$ & $30 / 54$ & 6-Apr \\
\hline
\end{tabular}

Table 5: Distribution of symptoms according to position of adenoid tissue $(n=120)$.

\begin{tabular}{|c|c|c|c|c|}
\hline Features & Grade A & Grade B & Grade C & Grade D \\
\hline Hearing impairment & 8-Feb & $20-\mathrm{Sep}$ & $66 / 68$ & $24 / 24$ \\
\hline Mouth breathing & 8-Mar & $14 / 20$ & $67 / 68$ & $24 / 24$ \\
\hline Snoring & 8-Mar & $20-\mathrm{Dec}$ & $66 / 68$ & $24 / 24$ \\
\hline Nasal discharge & 8-Feb & 20 -Jun & $44 / 68$ & $18 / 24$ \\
\hline
\end{tabular}

Table 6: Correlation between Adenoid size and Types of Tympanometry in the Left and Right Ears $(n=240)$.

\begin{tabular}{|c|c|c|c|c|c|}
\hline & Tympanometry type & Grade I & Grade II & Grade III & Grade IV \\
\hline \multirow{3}{*}{ Right Ear } & A & 10 & 5 & 4 & 0 \\
& B & 3 & 14 & 45 & 5 \\
Left Ear & C & 3 & 25 & 5 & 1 \\
& A & 11 & 8 & 2 & 4 \\
& B & 5 & 20 & 3 & 2 \\
\hline
\end{tabular}

Table 7: Correlation between Adenoid position and Types of Tympanometry in the Left and Right Ears $(n=240)$.

\begin{tabular}{|c|c|c|c|c|c|}
\hline & Tympanometry type & Grade A & Grade B & Grade C & Grade D \\
\hline \multirow{3}{*}{ Right Ear } & A & 7 & 5 & 8 & 0 \\
& B & 0 & 13 & 55 & 22 \\
Left Ear & C & 1 & 2 & 5 & 2 \\
& A & 8 & 15 & 58 & 23 \\
\hline
\end{tabular}

Table 8: Postoperative correlation of tympanometry with adenoid grading according to size $(n=240)$.

\begin{tabular}{|c|c|c|c|c|c|}
\hline \multirow{3}{*}{ Right Ear } & Tympanometry type & Grade I & Grade II & Grade III & Grade IV \\
\hline & A & 15 & 33 & 39 & 5 \\
\cline { 2 - 6 } & B & 1 & 6 & 11 & 1 \\
\hline
\end{tabular}




\begin{tabular}{|c|c|c|c|c|c|}
\hline \multirow{3}{*}{ Left Ear } & A & 14 & 34 & 45 & 6 \\
\cline { 2 - 6 } & B & 2 & 6 & 7 & 0 \\
\cline { 2 - 6 } & C & 0 & 4 & 2 & 0 \\
\hline
\end{tabular}

Table 9: Postoperative correlation of tympanometry with adenoid grading according to position $(n=240)$.

\begin{tabular}{|c|c|c|c|c|c|}
\hline & Tympanometry type & Grade A & Grade B & Grade C & Grade D \\
\hline \multirow{3}{*}{ Right Ear } & A & 8 & 16 & 61 & 21 \\
\cline { 2 - 6 } & B & 0 & 3 & 6 & 3 \\
\cline { 2 - 6 } & C & 0 & 1 & 0 & 20 \\
\hline \multirow{3}{*}{ Left Ear } & A & 8 & 15 & 5 & 4 \\
\cline { 2 - 6 } & B & 0 & 0 & 1 & 0 \\
\hline
\end{tabular}

After adenoidectomy with myringotomy patients were followed up every 3 months for 1 year. During follow up, patients were advised for follow up tympanometry. After 3 months of surgery, majority of tympanometry curve was shifted from type B to type A. (Table 8) shows, in case of Grade III, type B tympanometry reduced from 45 to $11(83 \%$ to $20 \%)$ in right ears; 49 to 7 . (90\% to $12 \%$ ) in left ears. Again, table 9 shows, in case of Grade C, type B tympanometry reduced from 55 to $6(80 \%$ to $8 \%$ ) in right ears; 58 to $5(85 \%$ to $7 \%)$ in left ears. (Table 8,9$)$ shows Postoperative correlation of tympanometry with adenoid grading.

\section{Discussion}

Otitis media with effusion (OME) is the accumulation of serous or mucoid collection within the middle ear and sometimes the mastoid air cell system. OME is both the most common childhood disease for which medical attention is sought and the most common indication for surgery. Duration of OME varies as it may be acute, which is less than 3 weeks, subacute which is between 3 weeks and 3 months, or chronic which is more than 3 months duration.13 About $90 \%$ of children might have OME at some time before school age which is more frequent between 6 months and 4 years of age [13]. The period of maximum lymphoid hyperplasia of the nasopharynx nearly coincides with the peak age of incidence of recurrent OME [14].

Adenoid hypertrophy is a common problem in childhood. It plays an important role in pathogenesis of OME, a common cause of hearing impairment in young children [15]. Adenoids can cause OME by either mechanical obstruction of the Eustachian tube (ET) leading to negative pressure in the middle ear [16] or by acting as a reservoir for infection in upper respiratory tract infection with edema of pharyngeal opening of ET [17]. The treatment for OME includes watchful waiting or observation, myringotomy, tympanostomy tube and adenoidectomy. However, opinions regarding the risks and benefits of adenoidectomy vary and the management of OME remains controversial. In some studies, adenoidectomy has been proved to be effective in preventing recurrence of $\mathrm{OME}$, recurrent $\mathrm{AOM}$, or the need for repeated tympanostomy tubes $[18,19]$.
In our study, majority of patients (46\%) were found in 6-9 years of age group which is similar to that of a study [20]. Male female ratio of patients in this series is 1.4: 1 which is in accordance with the study (1.92:1) of other workers [21]. In this study two methods of grading were adopted; according to size of adenoid tissue which was measured by X-ray soft tissue nasopharynx; and another one according to relation of adenoid with torus tubarius, vomer and soft palate seen by flexible nasoendoscope. In both grading methods majority of population remained in Grade III (45\%) and Grade C (56.67\%). This study showed significant association between grade III and grade C adenoid hypertrophy and otitis media with effusion when compared with other grades of adenoid hypertrophy. This suggests or shows that increasing grade of adenoid hypertrophy is important predictor in establishment of otitis media with effusion in patient with adenoid hypertrophy.

Among the presenting symptoms most common symptoms of the patients were hearing impairment and mouth breathing. These symptoms were mild in case of Grade I and Grade A categories. In case of Grade III and IV patients $100 \%$ presented with hearing impairment. Mouth breathing and snoring were prevalent in $96 \%$ or more patients in Grade III and IV categories. In case of Grade C and Grade D, hearing impairment was present in $97 \%$ and $100 \%$ patients respectively. Mouth breathing and snoring were present in $97 \%$ or more patients in Grade C and Grade D. These findings of this series are consistent with the findings of a reported series [22]. The series showed hearing impairment and mouth breathing in $83.00 \%$ and $77.00 \%$ cases respectively. This indicates symptoms became prominent with the increase of adenoid size, as well as close relation to torus tubarius, vomer and soft palate.

Tympanometry is one of the most useful quantitative measures for diagnosing middle ear effusion [23]. Orchik et al considered type B tympanometry as the most sensitive and specific test in detecting middle ear effusion [24]. In this study, type B tympanometry was considered as evidence of fluid effusion in the middle ear. Type $\mathrm{C}$ also was considered as some fluid in the middle ear, while type A was considered normal. In this study, grade III and IV adenoid hypertrophy showed a highly significant correlation with type B 
tympanometry, as well as grade $\mathrm{C}$ and $\mathrm{D}$. This correlates to Timna and Chandrika study, where grade III adenoid hypertrophy showed higher number of cases of OME [25]. Vijayan et al stated that with increasing the grade of adenoid size, the more chance of fluid level and OME, where they found that grade IV adenoid hypertrophy was associated with a more likely incidence of OME [9]

With more the lesions abutting torus tubarius, the more likely the incidence of OME and more likely the need for adenoidectomy to relieve the hazardous effect of adenoid on the ear [25]. This comes as a support for this study, where with increasing the grade of adenoid size and consequently, the relation and proximity to torus tubarius, the more likely the affection with OME. All the cases were subjected to adenoidectomy with myringotomy without any tube/ grommet insertion and were observed every 3 months, at which time an examination of the ear, nasopharynx and tympanometry were performed for 1 year or until tympanometry type A curve occurred. If recurrence of OME occurred then revision surgery was done (myringotomy + grommet insertion).

After 3 months of surgery, majority of tympanometry curve was shifted from type B to type A. In case of Grade III, type B tympanometry reduced from 45 to 11 (83\% to $20 \%$ ) in right ears; 49 to 7 (90\% to $12 \%$ ) in left ears. Again, in case of Grade C, type B tympanometry reduced from 55 to $6(80 \%$ to $8 \%)$ in right ears; 58 to $5(85 \%$ to $7 \%)$ in left ears. This change was significant. The greater the size of the adenoid, after adenoidectomy, more improvement noticed in tympanometry curve. The remaining ear, with type B or C tympanometry curve, were subjected to revision surgery which was myringotomy with grommet insertion.

Wallace's meta-analyses indicated that adenoidectomy alone, as an adjunct to myringotomy, or combined with tubes, reduced OME and improved hearing in comparison with either myringotomy or watchful waiting. And his research showed that tubes and adenoidectomy reduce time with OME and improve hearing in the short-term [26]. Wang Mao-Che found that adenoidectomy has protective effect in preventing tympanostomy tube re-insertions compared to tympanostomy tubes alone, especially for children older than 4 years old and who needed tubes for the first time [27]. These studies support that adenoidectomy is effective.

Our research also shows a benefit of adenoidectomy in the removal of middle ear effusion in children with OME. To efficiently assess the efficacy and security of adenoidectomy for otitis media with effusion in children, future research is needed.

\section{Conclusion}

Otitis media with effusion is a very common childhood disease. This study confirms the high correlation between adenoid size and incidence of OME. There is a highly significant relation between higher grades of adenoid hypertrophy and tympanometry type B. Our research shows a benefit of adenoidectomy in the removal of middle ear effusion in children with OME.
Result of this study may not be the actual picture of overall situation due to many limitations is this study. Still it can be concluded that enlarged adenoids has a definite role in causing OME and conductive hearing impairment. So early diagnosis and treatment of enlarged adenoids can be encouraged to decrease the actual incidence, morbidity and complications of otitis media with effusion and thus conductive hearing impairment in childhood.

\section{Acknowledgement}

None.

\section{Conflict of Interest}

No conflict of interest.

\section{References}

1. Paradise JL, Rockette HE, Colborn DK, Bernard BS, Smith CG, et al. (1997) Otitis media in 2253 Pittsburgh-area infants: prevalence and risk factors during the first two years of life. Pediatrics 99: 318-333.

2 Casselbrant ML, Mandel EM (2003) Epidemiology. In: Rosenfield RM, Bluestone CD (Eds.), Evidence-based otitis media. ( $2^{\text {nd }}$ Edn.), Hamilton: Ontario, BC Decker pp: 147-162.

3 Stool SE, Berg AO, Berman S (1994) Otitis Media with Effusion in Young Children. Clinical Practice Guideline, Number 12. AHCPR Publication No. 94-0622. Rockville, MD: Agency for Health Care Policy and Research, Public Health Service, US Department of Health and Human Services, USA

4 Sadler TW (1995) Langman's Medical embryology, Baltimore, Maryland, USA, Willams and Wilkins pp: 347-354

5 Hibbert J, Whitehouse GH (1978) The assessment of adenoidal size by radiological means. Clin otolaryngol Allied Sci 3: 43-47.

6 Abdullah B, Hassan S (2007) Clinical and audiological profiles in children with chronic otitis media with effusion requiring surgical intervention Malays. Malays J Med Sci 14(2): 22-27.

7 Pasha A (2006) Comparative Study Between Endoscopic Assisted Adenoidectomy and Conventional Adenoidectomy. Rajiv Gandhi University of Health Sciences, Karnataka, Bangalore, India.

8 Christopher JL, Carol AS, Arie R (2000) Eustachian tube endoscopy in patients with chronic ear disease. Laryngoscope. 110(11): 1884-1889.

9. Vijayan A, Ramakrishnan VR, Manjuran TJ (2018) Relationship between adenotonsillar hypertrophy and otitis media with effusion. Int J Cont Med Res 5(2): B1-B5.

10. Clemens J, Mc Murray JS (1998) Electrocautery versus curette adenoidectomy: comparison of post-operative results. Int J Paediatr Otorhinolaryngol 43(2):115-122.

11. Wang DY, Bernheim N, Kaufman L, Clement P (1997) Assessment of adenoid size in children by fiber optic examination. Clin Otolaryngol Allied Sci 22(2):172-177.

12. Parikh SR, Coronel M, Lee JJ, Brown SM (2006) Validation of a new grading system for endoscopic examination of adenoid hypertrophy. Otolaryngol Head Neck Surg 135(5): 684-687.

13. Bluestone CD, Klein JO (1995) Otitis Media in Infants and Children Philadelphia: WB Saunders; Definitions, terminology and classification (2 $2^{\text {nd }}$ Edn.) 1-201.

14. Macintyre EA, Karr CJ, Koehoorn M, Paul Demers, Lillian Tamburic, et al. (2010) Otitis media incidence and risk factors in a population-based birth cohort. Paediatr Child Health 15(7): 437-442.

15. Bluestone CD (1975) Obstructive adenoids in relation to otitis media. Ann Otol Rhinol Laryngol 84(19): 44-48. 
16. Di Francesco R, Paulucci B, Nery C, Bento RF (2008) Craniofacial morphology and otitis media with effusion in children. Int J Ped Otorhinolaryngol 72(8): 1151-1158.

17. Dhingra PL (2009) Eustachian tube and its disorders, in Diseases of the ear, nose and throat, Gopsons (4 ${ }^{\text {th }}$ Edn.), New Delhi, India p: 59-60.

18.MRC Multicenter Otitis Media Study Group (2012) Adjuvant adenoidectomy in persistent bilateral otitis media with effusion: hearing and revision surgery outcomes through 2 years in the TARGET randomized trial. Clin Otolaryngol 37: 107-116.

19. Gleinser DM, Kriel HH, Mukerji S (2011) The relationship between repeat tympanostomy tube insertions and adenoidectomy. Int J Pediatr Otorhinolaryngol 75: 1247-1251.

20. (1992) Diseases of the middle ear. In: Gray RF, Hawthorne N1 (Eds.), Synopsis of Otolaryngology, Bombay, KM Varghese, pp: 98-128.

21. Pukarder J, Sipila M, Karma P (1984) Occurance of and risk factors in acute otitis media. In: Lim DJ, Bluestone CD, Klein 10, Nelson JD (Eds.) Recent advances in Otitis media with effusion, philadelphia, BC Decker, Inc p: 9-13.

22. Pruzanski S (1995) Roentgencephalometric studies of tonsils and adenoids in normal and pathologic states. Ann Otolaryngol 84(19): 5562.
23. Iacovou E, Vlastarakos PV, Ferekidis E, Nikolopoulos TP (2013) Multifrequency tympanometry: clinical applications for the assessment of the middle ear status. Indian J Otolaryngol Head Neck Surg 65(3): 283-287.

24. Orchik OJ, Dunn JW, McNutt L (1978) Tympanometry as a predictor of middle ear effusion. Arch Otolaryngol 104(1): 4-6.

25. Timna CJ, Chandrika D (2018) Role of adenoid hypertrophy in causation of chronic middle ear effusion. Int J Otorhinolaryngol Head Neck Surg 4(1): 203-209.

26. Wallace IF, Berkman ND, Lohr KN, Harrison MF, Kimple AJ, et al. (2014) Surgical Treatments for Otitis Media with Effusion: A Systematic Review. Pediatrics 133: 296-311.

27. Wang MC, Wang YP, Chu CH, Tu TY, Shiao AS, et al. (2014) The Protective Effect of Adenoidectomy on Pediatric Tympanostomy Tube ReInsertions: A Population-Based Birth Cohort Study. PLoS One 9: 1-7. 